\title{
Sensitivity of the Single Particle Soot Photometer to different black carbon types
}

\author{
M. Laborde, P. Mertes, P. Zieger, J. Dommen, U. Baltensperger, and M. Gysel \\ Laboratory of Atmospheric Chemistry, Paul Scherrer Institute, PSI, 5232 Villigen, Switzerland \\ Correspondence to: M. Gysel (martin.gysel@psi.ch) \\ Received: 29 November 2011 - Published in Atmos. Meas. Tech. Discuss.: 17 January 2012 \\ Revised: 13 April 2012 - Accepted: 21 April 2012 - Published: 11 May 2012
}

\begin{abstract}
Black carbon (BC) is now mainly of anthropogenic origin. It is the dominant light absorbing component of atmospheric aerosols, playing an important role in the earth's radiative balance and therefore relevant to climate change studies. In addition, $\mathrm{BC}$ is known to be harmful to human beings making it relevant to policy makers. Nevertheless, the measurement of $\mathrm{BC}$ remains biased by the instrument-based definition of BC. The Single Particle Soot Photometer (SP2), allows the measurement of the refractory $\mathrm{BC}(\mathrm{rBC})$ mass of individual particles using laser-induced incandescence. However, the SP2 needs an empirical calibration to retrieve the $\mathrm{rBC}$ mass from the incandescence signal and the sensitivity of the SP2 differs between different BC types. Ideally, for atmospheric studies, the SP2 should be calibrated using ambient particles containing a known mass of ambient rBC. However, such "ambient BC" calibration particles cannot easily be obtained and thus commercially available BC particles are commonly used for SP2 calibration instead. In this study we tested the sensitivity of the SP2 to different $\mathrm{BC}$ types in order to characterize the potential error introduced by using non-ambient $\mathrm{BC}$ for calibration. The sensitivity of the SP2 was determined, using an aerosol particle mass analyzer, for $\mathrm{rBC}$ from thermodenuded diesel exhaust, wood burning exhaust and ambient particles as well as for commercially available products: Aquadag ${ }^{\circledR}$ and fullerene soot.

Thermodenuded, fresh diesel exhaust has been found to be ideal for SP2 calibration for two reasons. First, the small amount of non-BC matter upon emission reduces the risk of bias due to incomplete removal of non-BC matter and second, it is considered to represent atmospheric $\mathrm{rBC}$ in urban locations where diesel exhaust is the main source of BC. The SP2 was found to be up to $16 \%$ less sensitive to rBC from
\end{abstract}

thermodenuded ambient particles $(\leq 15 \mathrm{fg})$ than $\mathrm{rBC}$ from diesel exhaust, however, at least part of this difference can be explained by incomplete removal of non-refractory components in the thermodenuder. The amount of remaining nonrefractory matter was estimated to be below $30 \%$ by mass, according to a comparison of the scattering cross sections of the whole particles with that of the pure BC cores. The SP2 sensitivity to $\mathrm{rBC}$ from wood burning exhaust agrees with the SP2 sensitivity to $\mathrm{rBC}$ from diesel exhaust within an error of less than $14 \%$ ( $\leq 40 \mathrm{fg})$.

If, due to experimental restrictions, diesel exhaust cannot be used, untreated fullerene soot was found to give an SP2 calibration curve similar to diesel exhaust and ambient $\mathrm{rBC}$ (within $\pm 10 \%$ for a $\mathrm{rBC}$ mass $\leq 15 \mathrm{fg}$ ) and is therefore recommended although two different batches differed by $\sim 14 \%$ between themselves. In addition, the SP2 was found to be up to $40 \%$ more sensitive to Aquadag ${ }^{\circledR}$ than to diesel exhaust rBC. Therefore Aquadag ${ }^{\circledR}$ cannot be recommended for atmospheric application without accounting for the sensitivity difference. These findings for fullerene soot and Aquadag ${ }^{\circledR}$ confirm results from previous literature.

\section{Introduction}

The interest of atmospheric science in black carbon (BC) aerosol particles has been growing in the recent years due to the fact that it is now mainly of anthropogenic origin and due to its impact on both climate and health. BC being the dominant light absorbing component of atmospheric aerosols, it is playing an important role in the earth's radiative balance and is therefore relevant to climate change (Ramanathan and Carmichael, 2008; Bond and Bergstrom, 2006). In addition, 
BC is known to be harmful to human beings (von Klot et al., 2011) making it relevant to policy makers. Despite these interests, the quantitative measurement of $\mathrm{BC}$ remains a challenge due to the persistent ambiguity of the instrument-based definition of BC, even though recent studies show that consistent results can be achieved with different methods (Kondo et al., 2011).

Indeed, the utilized method currently defines the BC's appellation such that elemental carbon (EC) designates the result of a measurement based on its thermal properties and $\mathrm{BC}$ designates the result of a measurement based on its optical properties. Both methods are currently being used and have both their specific advantages. EC measurements, often optically corrected, have the advantage of directly measuring mass but they can be biased by charring artefacts in the presence of organic carbon (OC; Schmid et al., 2001). The second method, used in the photoacoustic spectrometer (Arnott et al., 1999), Aethalometer, multi angle absorption photometer and particulate soot absorption photometer (Slowik et al., 2007), is based on an indirect measurement of BC mass via its light absorption and has the advantage of being an online measurement. However, the measurement can be biased by using an incorrect value for the mass absorption coefficient (MAC), which is required to retrieve BC mass from absorption measurements (Petzold et al., 1997).

An alternative method, based on laser-induced incandescence (LII), implemented in the single particle soot photometer (SP2; Stephens et al., 2003), has been used several times to measure refractory $\mathrm{BC}(\mathrm{rBC})$ mass (e.g. Matsui et al., 2011; Liu et al., 2010; Schwarz et al., 2008a). This technique indirectly quantifies the mass of $\mathrm{rBC}$ in single particles by measuring the intensity of the thermal radiation emitted at the $\mathrm{rBC}$ boiling point. The $\mathrm{rBC}$ is therefore defined as the most refractory fraction of carbonaceous material retained on the particle until incandescence is reached at $\sim 4000 \mathrm{~K}$. The $\mathrm{rBC}$ mass retrieved has been shown to be independent of its mixing state and morphology (Moteki and Kondo, 2007; Slowik et al., 2007). However, an empirical calibration linking the measured incandescence signal to the $\mathrm{rBC}$ mass is needed. The calibration curve is known to be almost linear but is also influenced by the chemical structure of $\mathrm{rBC}$ (Moteki and Kondo, 2010). This leads to an uncertainty in the rBC quantification if the chemical structure of the rBC sampled differs from the chemical structure of that used to calibrate the SP2.

An ideal calibration material for the SP2 consists of $100 \%$ $\mathrm{rBC}$ with equal chemical structure as ambient $\mathrm{rBC}$. Such particles could be selected by their mass, all of which is $\mathrm{rBC}$, using an aerosol particle mass analyzer (APM; Ehara et al., 1996) or a couette centrifugal particle mass analyzer (CPMA; Olfert and Collings, 2005) and fed to the SP2 in order to determine the calibration curve, i.e. the relationship between incandescence signal and $\mathrm{rBC}$ mass.

SP2 calibrations based on ambient $\mathrm{rBC}$, have only been done by one research group so far (Moteki and Kondo, 2010), mainly for two reasons. First, only very few research groups have access to a particle mass analyser. Second, ambient BC particles do not consist of $100 \% \mathrm{rBC}$. Heating ambient particles to remove non-BC components using a thermodenuder may provide nearly pure ambient $\mathrm{rBC}$, however, incomplete removal of non-BC components with high boiling points may bias the calibration. Instead, the common way to calibrate SP2s is to measure nebulized aqueous suspensions of commercially available BC products such as fullerene soot, Aquadag ${ }^{\circledR}$ or glassy carbon. Calibration particles of a certain mobility diameter are then selected using a differential mobility analyzer (DMA) and the corresponding rBC mass is calculated using effective density data from literature (Gysel et al., 2011; Moteki and Kondo, 2010). The uncertainties of this common practice lie in potential differences between the SP2's sensitivity to the calibration material and the investigated sample as well as in the accuracy of the effective density data. The accuracy of SP2 measurements could be improved if a large quantity of a calibration material with stable effective density and equal incandescence signal per particle mass as ambient rBC was available. Fullerene soot has been shown to produce similar SP2 calibration curves as ambient $\mathrm{rBC}$ from Tokyo while Aquadag ${ }^{\circledR}$ produces a higer signal per mass (Moteki and Kondo, 2010). However, this observation remains to be confirmed with measurements in different locations featuring contributions by possibly different $\mathrm{BC}$ sources such as diesel exhaust, biomass burning, and trash burning.

In this study we investigate the sensitivity of the SP2 to ambient BC and compare it to fullerene soot, Aquadag ${ }^{\circledR}$ as well as BC obtained from a diesel car and a log wood burner. The goals of this study are first the identification of suitable SP2 calibration materials and second the quantification of the SP2 measurement uncertainties resulting from uncertainties of the SP2 calibration. A new method using the time-resolved scattering cross section measurement for the identification of thin non-refractory coatings is also presented.

\section{Method}

\subsection{Single particle soot photometer}

The SP2 instrument is available commercially (Droplet Measurement Technology, Boulder, USA). Its operating principles have been described previously (e.g. Moteki and Kondo, 2007; Schwarz et al., 2006; Stephens et al., 2003). Briefly, the particles sampled by the SP2 are directed through a highintensity continuous intra-cavity laser beam (wavelength $\lambda=1064 \mathrm{~nm}$ ) in order to bring BC particles to incandescence. The $\mathrm{rBC}$ mass in single particles is indirectly quantified by measuring the intensity of the thermal emission from the rBC core at its boiling point.

The thermal radiation is detected in the SP2 by two photomultiplier tubes (PMT) equipped with optical filters 
(broadband transparent between $\sim 350 \mathrm{~nm}$ and $\sim 800 \mathrm{~nm}$ and narrowband transparent between $\sim 630 \mathrm{~nm}$ and $\sim 800 \mathrm{~nm}$ ). In addition, the light elastically scattered by the particle is measured by an avalanche photodiode (APD), and a position sensitive detector (PSD, described in more details hereafter) is used to determine the position of the particle in the laser beam.

Only broadband channel data are reported here for several reasons. First, the broadband channel is equally configured for all SP2 instruments and is commonly used as the primary channel for $\mathrm{rBC}$ mass quantification, while the configuration of the narrowband channel differs between different SP2s. Second, it presents the advantages of having a higher signal to noise ratio and of covering most of the atmospherically relevant diameter range. In addition to the mass of $\mathrm{rBC}$ contained in the particle, the SP2 can also provide information on the amount of coating.

\subsection{Detection of non-refractory coatings}

In order to retrieve the amount of coating on the particles, previous studies have compared the time lag between the scattering signal peak and the incandescence signal peak. While this approach (referred to as the delay time method) is able to identify thickly coated particles, it cannot distinguish pure $\mathrm{rBC}$ particles from $\mathrm{rBC}$ particles with thin to medium coating. Gao et al. (2007) then developed the PSD, which allows determining the coated particle's optical diameter, from the initially unperturbed scattering signal when the particle enters the laser beam, before the coating starts evaporating. The coating thickness can be calculated by subtracting the mass equivalent $\mathrm{rBC}$ core diameter (retrieved from the incandescence measurement) from the optical diameter of the coated particle with a lower detectable limit of 25 -nm thickness of coating (Schwarz et al., 2008b). However, the accuracy of this approach depends on the acurracy of the detectors's calibration as well as on further assumptions such as e.g. the applicability of a concentric coated sphere Mie model or the refractive indices of $\mathrm{rBC}$ core and coating. Moteki and Kondo (2008) introduced an alternative method to determine the time-resolved scattering cross section of the particles, which is essentially similar to that of Gao et al. (2007), except that the PSD is not required.

\subsubsection{Time-resolved scattering cross section method}

In this study, a thermodenuder (heated to $400^{\circ} \mathrm{C}$ ) was used to obtain pure $\mathrm{rBC}$ cores from e.g. diesel exhaust for SP2 calibration. In order to test whether the thermodenuder completely removes the coatings from the $\mathrm{rBC}$ cores, a sensitive method, able to distinguish between pure $\mathrm{rBC}$ and thinly coated rBC core was needed. In Fig. 1 we present an approach that builds upon the method introduced by Gao et al. (2007). This method is freed from any instrument calibration factor and any assumptions on optical and physical particle properties.

The scattering signal measured by the SP2 is proportional to the differential scattering cross section of the recorded particle into the solid angle covered by the detector optics. For conciseness, we will hereafter just refer to the scattering cross section. Figure 1d (cyan line) shows the scattering cross section of an ambient particle at different times throughout the laser beam. The time-resolved particle scattering cross section reflects the evolution of the particle diameter while it heats up in the laser beam. It will therefore decrease during the evaporation of the coating and during the evaporation of the $\mathrm{rBC}$ core and remains stable at other times, when the particle's diameter stays unchanged. The first plateau, before coating evaporation, defines the scattering cross section of the whole coated BC particle. The second plateau, between coating evaporation and $\mathrm{rBC}$ core evaporation, defines the scattering cross section of the pure $\mathrm{rBC}$ core. The presence of a coating is here identified when the scattering cross section of the whole particle is greater than that of the pure rBC core, whereas the two values will be equal for uncoated particles.

In more details, the intensity profile of the laser beam along the flight path of the particles and the position of the particle in the laser beam is first needed. Then, the timeresolved particle cross section can be calculated by dividing the scattering signal at a time $t$ by the laser beam intensity at the particle's position in the laser beam.

The laser intensity profile can be derived from the measurement of purely scattering particles. Indeed, nonabsorbing particles cross the laser beam unaltered, namely no heating or evaporation occurs. The scattering signal $S(t)$ is then always proportional to the laser intensity, and follows an almost Gaussian function which defines the laser beam shape. The shape of the scattering signal is equal for all purely scattering particles, except for the amplitude and noise, as all particles sampled by the SP2 cross the laser beam with almost equal velocity. The exact laser intensity profile as shown in Fig. 1a can therefore be determined with statistics of normalised scattering signal shapes obtained from purely scattering particles. The intensity profile is normally stable over time-scales of days, unless contamination of laser optics or alignment drifts occurs.

The position of the particle in the laser beam is also needed. For purely scattering particles, the centre of the laser beam, $t_{\text {centre }}$, is identified as the time when the scattering signal is maximal. For evaporating particles, the position can be obtained using the PSD as described in Gao et al. (2007). Briefly, the PSD consists of a modified APD, detecting the elastically scattered light, where the signal from half of the detection area is inverted. Therefore, the PSD signal (in green in Fig. 1b) starts negative and crosses the baseline towards positive values at the time, $t_{\text {split }}$, at which the scattered light falls between the non-inverted and inverted detector halves. $t_{\text {split }}$ corresponds to a fixed position in the laser beam and the time difference $\Delta t_{\text {split } 2 \text { centre }}$ between the split point $t_{\text {split }}$ and 
a)

b)

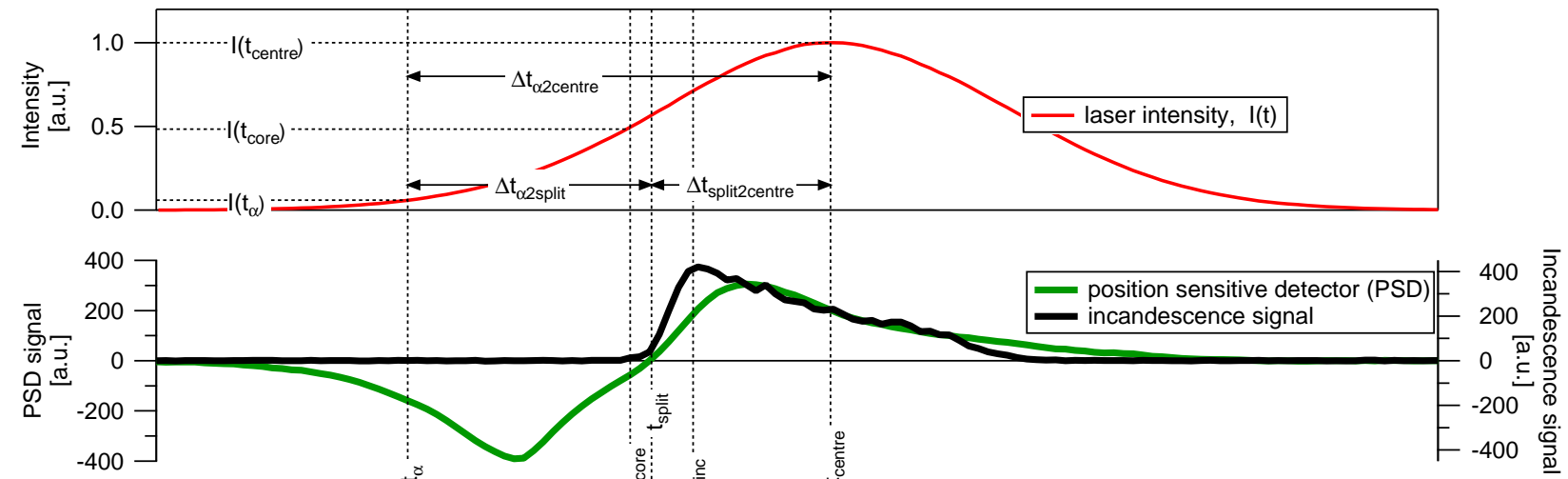

c)

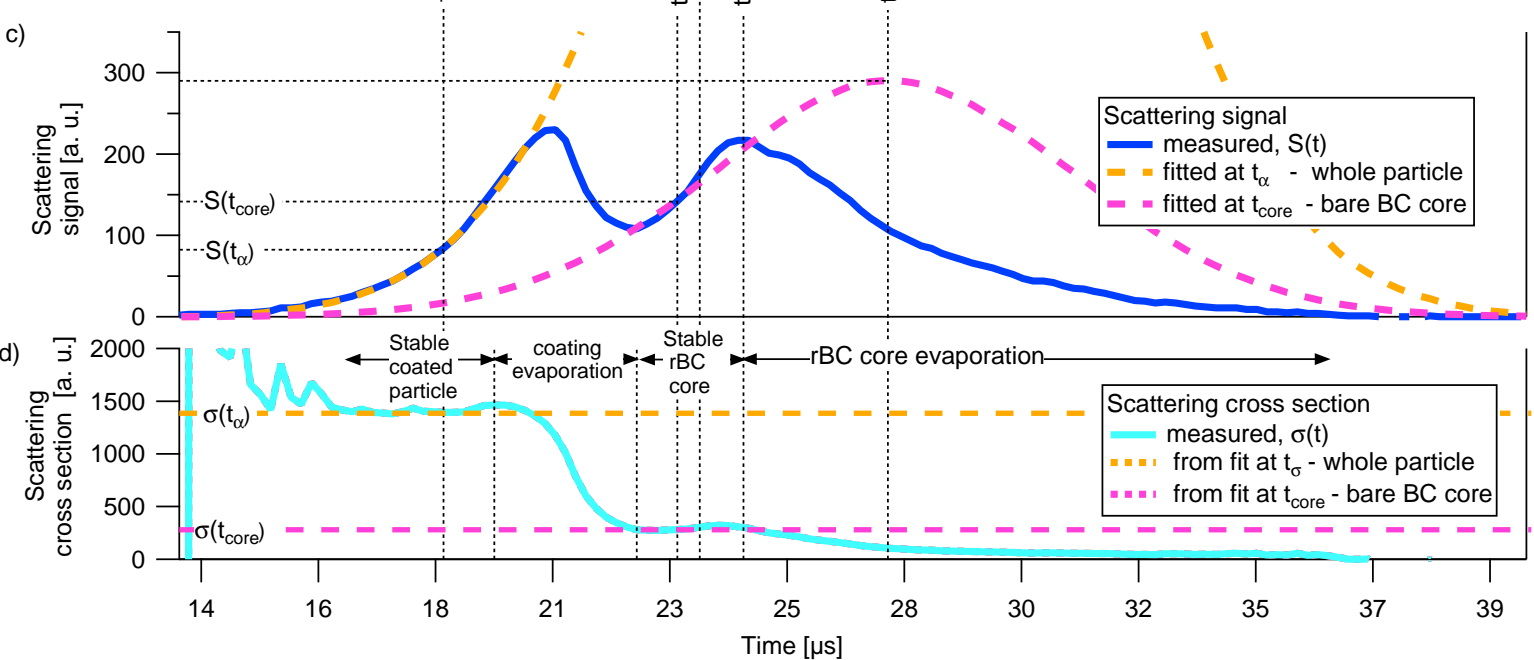

Fig. 1. Example for a rBC containing particle. (a) Laser beam intensity profile (b) incandescence and position sensitive signals (c) scattering signals (d) scattering cross section obtained by dividing scattering signal by laser intensity profile.

the laser centre $t_{\text {centre }}$ remains constant as all particles have almost the same velocity:

$\Delta t_{\text {split } 2 \text { centre }}=t_{\text {centre }}-t_{\text {split }}$.

BC containing particles shrink by evaporation when crossing the laser beam, therefore the scattering signal only follows the almost Gaussian shape described for purely scattering particles early in the laser beam. The maximum of the scattering signal is not reached at the laser centre (blue line in Fig. 1c) thus $t_{\text {centre }}$ cannot be directly obtained for BC containing particles. Nevertheless the time difference:

$\Delta t_{\alpha 2 \text { split }}=t_{\text {split }}-t_{\alpha}$

between any time, $t_{\alpha}$, and the split point can be calculated for all particles, as the PSD provides $t_{\text {split }}$ also for BC containing particles (green line in Fig. 1b). The time difference,

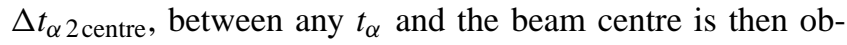
tained as

$\Delta t_{\alpha 2 \text { centre }}=\Delta t_{\alpha 2 \text { split }}+\Delta t_{\text {split } 2 \text { centre }}=t_{\text {split }}-t_{\alpha}+\Delta t_{\text {split } 2 \text { centre }}$

where $\Delta t_{\text {split } 2 \text { centre }}$ is determined from purely scattering particles as described above (Eq. 1).
Knowing the position of the particle at a certain time, $t_{\alpha}$, relative to the laser centre and knowing the normalised laser intensity profile, $I(t)$, the laser intensity $I\left(t_{\alpha}\right)$, to which the particle is exposed at that time, is then also known.

The laser intensity for any other time $t$ can be calculated in the same way, and the scattering cross section $\sigma(t)$ is obtained by dividing the measured scattering amplitude by the corresponding normalised laser intensity:

$\sigma(t)=\frac{S(t)}{I(t)} I\left(t_{\text {centre }}\right)$.

The normalisation factor $I\left(t_{\text {centre }}\right)$ in Eq. (4) is chosen such that the relation $\sigma\left(t_{\text {centre }}\right)=S\left(t_{\text {centre }}\right)$ is fulfilled for purely scattering particles. This normalisation assures that absolute values of the scattering cross section can directly be obtained by multiplication of the normalised $\sigma(t)$ with the calibration factor of the scattering detector.

An example of $\sigma(t)$ for an ambient coated BC particle is shown in Fig. 1d (cyan line), which is essentially $S(t)$ (blue line in Fig. 1c) divided by $I(t)$ (Fig. 1a). When the particle enters the laser beam, $S(t)$ first follows the Gaussian laser intensity profile (scaled with the scattering cross section of 
the whole particle, dashed orange line in Fig. 1c), and $\sigma(t)$ remains constant at $\sim 1370$ units until about $t=19.6 \mu$ s (note, $\sigma(t)$ is unreliable at $t \leqslant 16 \mu$ s due to detection limits). This first plateau, indicated as $\sigma\left(t_{\alpha}\right)$, represents the coated BC particles' scattering cross section.

Then, the non-refractory coating evaporates from the $\mathrm{rBC}$ core between $\sim 19.6 \mu \mathrm{s}$ and $22.4 \mu \mathrm{s}$, resulting in a drop of $S(t)$ below the course of the Gaussian profile and thus a decrease of $\sigma(t)$.

The remaining pure $\mathrm{rBC}$ core further heats up after $22.4 \mu \mathrm{s}$ until it reaches its incandescence point at $t_{\text {inc }}=24.5 \mu \mathrm{s}$, identified by the peak intensity of the incandescence signal (black line in Fig. 1b). During this time window $\sigma(t)$ remains constant on a second plateau at $\sim 290$ units, and the scattering signal follows again the Gaussian laser intensity profile, but on a lower level (pink dashed line in Fig. 1c scaled to a maximum amplitude of 290 units). This second plateau of $\sigma(t)$, indicated as $\sigma\left(t_{\text {core }}\right)$, corresponds to the pure $\mathrm{rBC}$ core.

At $t>t_{\text {inc }}=24.5 \mu$ s the rBC core gradually evaporates resulting in a drop of $S(t)$ below the course of a Gaussian profile corresponding to the complete $\mathrm{rBC}$ core and consequently $\sigma(t)$ decreases further.

In this study, the laser intensity profile was determined on a daily basis by analysing the signals of several thousands purely scattering particles from an ambient sample. We will take interest in the scattering cross section at two particular times:

- $\sigma\left(t_{1} \%\right)$ : scattering cross section of the whole unaltered $\mathrm{BC}$ containing particle. The time $t_{1 \%}$ corresponds to the time at which the particle is exposed to $1 \%$ of the maximum laser intensity, i.e. $I\left(t_{1 \%}\right) / I\left(t_{\text {centre }}\right)=0.01$. This approach is essentially equivalent to a leading edge fit as described in Gao et al. (2007). The limit of $t_{1} \%$ has been chosen to be before the earliest observed onset of coating evaporation.

- $\sigma\left(t_{\text {core }}\right)$ : scattering cross section after complete evaporation of the non-refractory coatings but before the onset of the $\mathrm{rBC}$ core evaporation. $t_{\text {core }}$ is chosen just before the onset of the incandescence signal (Fig. 1b).

In the absence of any coating, the pure $\mathrm{BC}$ core diameter and the whole particle diameter are identical and consequently both scattering cross sections $\sigma\left(t_{\text {core }}\right)$ and $\sigma\left(t_{1} \%\right)$ should agree, within experimental uncertainty, while in the presence of coating $\sigma\left(t_{1} \%\right)$ should be greater than $\sigma\left(t_{\text {core }}\right)$. The comparison of these two values can be used to determine whether or not the thermodenuder is able to completely remove the coatings for the different investigated $\mathrm{BC}$ types.

\subsubsection{Sensitivity of the time-resolved scattering cross section method}

Although this method presents the advantage of being freed from assumptions on the particle's physical or chemical properties, several questions remain to be addressed: What is the resolution power of this approach in terms of distinguishing different volume fractions of coatings, both for individual particles and for the average of a sample? Is this method indeed more sensitive to thin coatings than previous methods? In order to answer these questions, we present a sensitivity analysis of the method, in Fig. 2, where the scattering cross section of the whole particle is compared to that of the pure $\mathrm{rBC}$ core as a function of coating volume fraction. The scattering cross sections are calculated using Mie theory and assuming a concentric coated sphere morphology (no coating for the pure $\mathrm{BC}$ core) and different pairs of refractive indices. The refractive index of $2.26+1.26 i$ for the $\mathrm{BC}$ core was chosen to represent the refractive index of ambient $\mathrm{BC}$ cores (Moteki et al., 2010) at the SP2's wavelength, while the extreme values of $3+2 i$ and $1.75+0.43 i$ should cover the whole range of possible values (Bond and Bergstrom, 2006). The refractive indices of 1.3, 1.5 and 1.7 for the coating were also chosen to represent a likely range (Nakayama et al., 2010).

The one-to-one line in Fig. 2 corresponds to an uncoated particle, independently of the refractive index. The ratio of the scattering cross sections (whole particle to $\mathrm{BC}$ core) increases to $\sim 1.1$ for a coating volume fraction of $10 \%$, with little dependence on refractive indices. The influence of refractive index starts to be important for a $20 \%$ coating volume fraction, where the ratio of scattering cross sections ranges between $\sim 1.2-1.4$. A coating volume fraction of $60 \%$ results in a scattering cross section ratio as high as $\sim 2.1-4.8$. Figure 2 illustrates that it should, for example, be feasible to distinguish particles with $30 \%$ coating volume fraction from particles with $\leq 10 \%$ or $\geq 60 \%$ using solely the time-resolved scattering signal. However, setting tighter bands will be difficult without additional knowledge on the true refractive indices, always bearing in mind that morphology effects introduce extra uncertainty.

The previous statement is only valid for determining the average coating of a particle ensemble by analysing the median of the scattering cross section ratios. The measurement uncertainty of an individual data point has also to be considered when making statements for single particles. As an example, the random noise of the scattering cross section ratio is considerable in the data set of this study. This is, for a good part, the result of a very early incandescence onset in the laser beam, which forced the scattering cross section of the whole particle to be determined using only the scattering signal up to $1 \%$ of the maximal laser intensity. Furthermore, the factor $I\left(t_{\text {centre }}\right) / I\left(t_{1} \%\right)$ in Eq. (4) becomes as large as 100 , and thus a scattering signal amplitude of only 2 units measured at $1 \%$ laser intensity translates to a $\sigma\left(t_{1} \%\right)$ of 200 units. For this reason, all $\sigma$ values smaller than 200 units are ignored in Figs. 4 and 7, which show experimental data.

The sensitivity analysis in Fig. 2 indicates that particles with $30 \%$ coating volume fraction can be distinguished from uncoated $\mathrm{BC}$ particles using the time-resolved scattering 


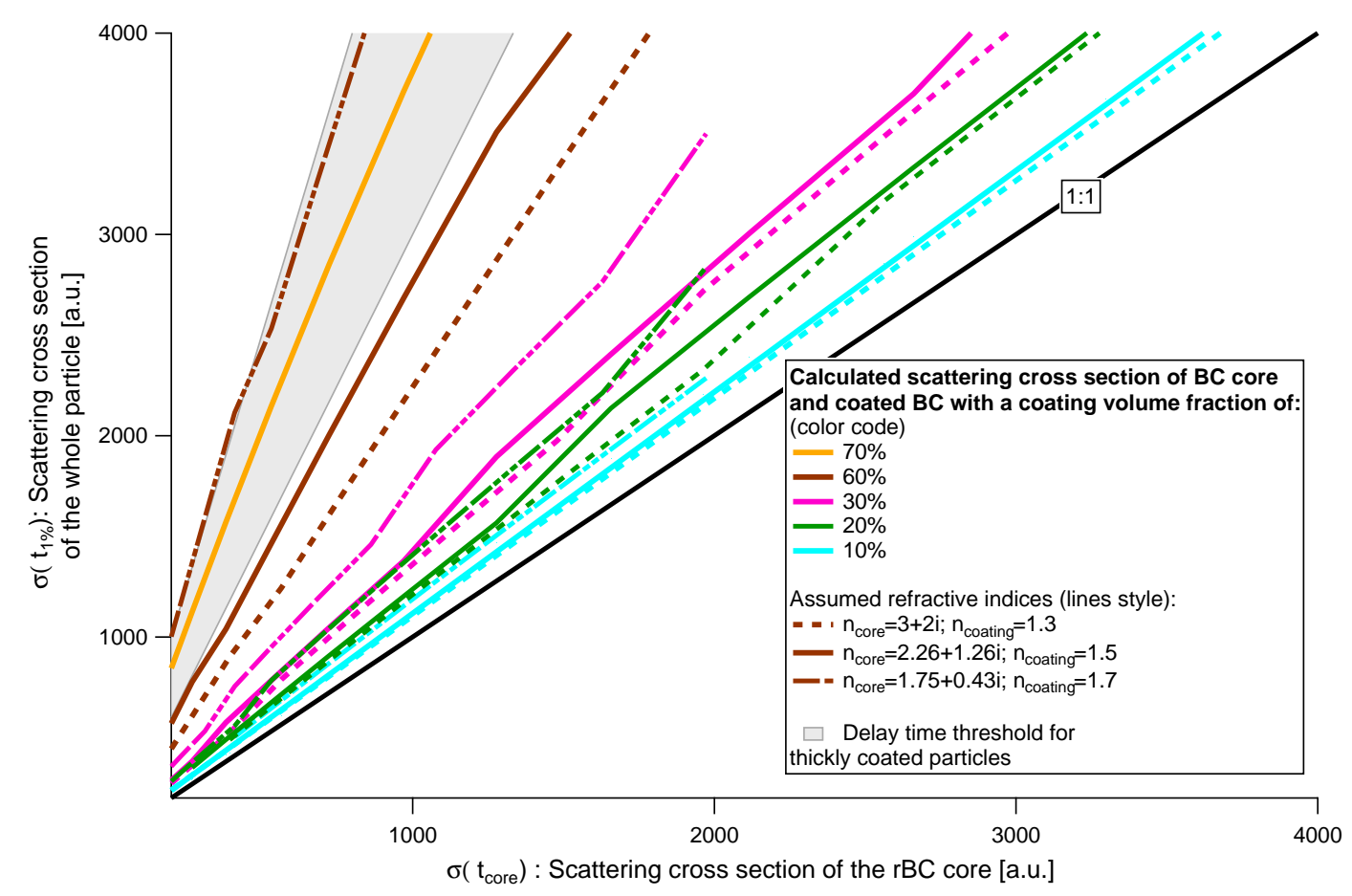

Fig. 2. Calculated scattering cross sections of the whole particle and the BC core. The scattering cross sections are calculated using Mie theory and assuming a concentric coated sphere morphology and different pairs of refractive indices (lines styles). The black line represents uncoated particles, independently of the refractive index, while the colored lines represent different coating volume fractions. The grey area represents the range of scattering cross section ratio for which the delay time threshold is reached (see Sect. 2.2.2).

cross section method. A comparison of this threshold to the classical LEO-fit approach (Gao et al., 2007) is hardly possible. Indeed the classical LEO-fit method determines the coating thickness by comparing the optical diameter of the whole particle (LEO-fit to the scattering measurement) with the mass equivalent diameter of the $\mathrm{BC}$ core (incandescence measurement). Therefore, the inferred coating thickness values depend on the scattering and incandescence detector calibrations, assumed refractive indices and applicability of the Mie model.

On the other hand, a comparison to the delay time approach (Moteki and Kondo, 2007) is possible. This method tests whether the scattering signal amplitude of the whole particle, measured when the coating starts evaporating, is higher than that of the pure $\mathrm{rBC}$ core, measured at the onset of incandescence $\left(t_{i n c}\right)$. Coating evaporation starts, for the SP2 as operated in this study, at 3-5 times lower laser intensity than incandescence. Consequently the whole particle must have a $\sim 3-5$ times larger scattering cross section than the pure $\mathrm{BC}$ core in order to reach the delay time threshold. This range of scattering cross section ratios is indicated as grey shading in Fig. 2. Comparison with the other lines in Fig. 2 shows that this threshold is expected to occur somewhere in the range of $\sim 70 \%$ coating volume fraction. A more detailed sensitivity analysis of the dependence of this threshold on the core size, refractive indices and laser intensity ratios is provided in Fig. S1 in the Supplement. The experimental data provided in Moteki and Kondo (2007) also indicate that at least a coating thickness of $70 \%$ is needed to reach the delay time threshold for "thickly coated" particles. These results clearly show that the delay time approach is not suitable to identify thin coatings.

\subsection{Black carbon samples}

The sensitivity of the SP2 has been characterized for different types of $\mathrm{BC}$ particles which are described in the following sections.

\subsubsection{Commercially available black carbon materials}

Aquadag ${ }^{\circledR}$ and fullerene soot are two commonly used SP2 calibration materials. The Aquadag ${ }^{\circledR}$ was obtained from Henkel Technologies (lot \#9054). Aquadag ${ }^{\circledR}$ is a colloidal suspension of aggregates of graphitic carbon, in which $\mathrm{sp}^{2}$ bonds are dominant, in water (Moteki and Kondo, 2010). Two batches of fullerene soot were obtained from Alfa Aesar: stock \#40971, lot \#FS12S011 and stock \#40971, lot \#L18U002. Fullerene soot particles are dominated by disordered or amorphous carbon with both $\mathrm{sp}^{3}$ and $\mathrm{sp}^{2}$ bonds present (Moteki and Kondo, 2010), and they also contain a minor fraction of fullerenes $(<10 \%$ according to Alfa Aesar's data sheet). 

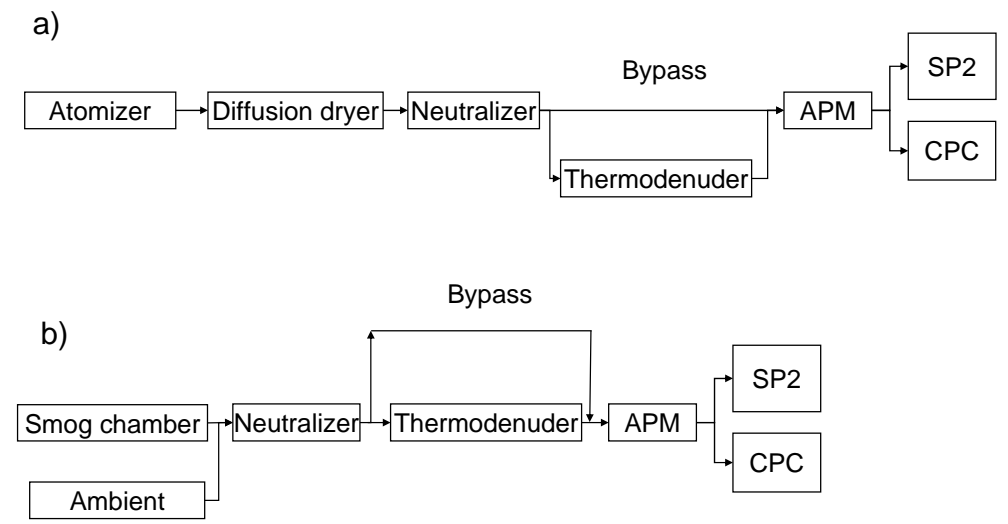

Fig. 3. Experimental setup for SP2 calibration using (a) an aqueous suspension of BC or (b) BC particles from the smog chamber/ambient air.

\subsubsection{Diesel soot}

Diesel exhaust BC was produced on 6 July 2011 and 13 July 2011 by running, on idle after cold start, an EURO 2 Volkswagen Transporter TDI Syncro from December 2000. Diesel exhaust was introduced for about 15 min into the Paul Scherrer Institute's (PSI) smog chamber via a heated inlet with dilution stage. More information on the vehicle used, on the characteristics of this vehicle's emissions and on the inlet system can be found in Chirico et al. (2010). The smog chamber then, simply served as a reservoir from which the exhaust was sampled in order to record a whole SP2 calibration curve under stable conditions.

\subsubsection{Wood burning soot}

Wood burning soot was produced on 8 July 2011 and 11 July 2011 by burning log wood in a burner (Attika Avant, 2009 , combustion chamber $\sim 0.037 \mathrm{~m}^{3}$ ) with well defined air flows to reach optimal combustion efficiency. A batch of burner exhaust from the flaming phase was filled into the PSI's smog chamber for roughly 15 minutes via a heated inlet with dilution stage. More information on the emission properties of this wood burner and on the heated system can be found in Heringa et al. (2011). Again, the smog chamber simply served as a reservoir from which the exhaust was sampled in order to record a whole SP2 calibration curve under stable conditions.

\subsubsection{Ambient BC}

Ambient BC containing particles were sampled for several hours on 7 July 2011 and 12 July 2011 at PSI, Villigen, Switzerland. This site can be considered to be representative of a polluted continental background station without dominant influence from local diesel or wood combustion sources.

\subsection{Experimental setup}

The setup shown in Fig. 3 was used to determine the SP2 calibration curves for the different $\mathrm{BC}$ types. The aim of this setup is to feed the SP2 with particles of known BC mass. A first step of the calibration measurements involved the generation of a (polydisperse) "pure" rBC aerosol. Sample specific particle generation procedures are discussed in the following.

Airborne samples of Aquadag ${ }^{\circledR}$ and fullerene soot were generated by atomization of an aqueous suspension followed by diffusion drying and subsequent neutralization using a ${ }^{85} \mathrm{Kr}$ source (Fig. 3a). Aquadag ${ }^{\circledR}$ and fullerene soot samples were not thermodenuded in standard SP2 calibrations.

Pure rBC from fresh diesel and wood combustion exhaust were sampled from the smog chamber, neutralized and thermodenuded (Fig. 3b). Likewise for rBC from ambient particles apart from directly sampling from the ambient air (Fig. 3b).

The thermodenuder (Burtscher et al., 2001) was used to remove the non-BC matter from the $\mathrm{BC}$ particles. The apparatus is composed of a volatilisation section made of a stainless steel tube (outer diameter $2 \mathrm{~cm}$; wall thickness $1 \mathrm{~mm}$, length $50 \mathrm{~cm}$ ) and is welded to a coaxial heating element. A regulated power supply controls the desorber temperature at $400^{\circ} \mathrm{C}$. The absorber section consists of stainless-steel gauze (diameter $2 \mathrm{~cm}$; length $50 \mathrm{~cm}$ ) supported in the centre of a cylindrical metal casing and filled with activated charcoal. The residence time of the aerosol in the heated section was approximately $18 \mathrm{~s}$ with a $0.421 \mathrm{~min}^{-1}$ flow rate. The possibility of artefacts from remaining non-BC matter after the thermodenuder will be discussed in Sect. 3.1.

In the second step of the calibration measurement, the pure $\mathrm{rBC}$ particles were fed into the APM (Kanomax Model APM-II 3601). The APM selects particles by their mass to charge ratio, based on the balance between centrifugal force and electrostatic force (multiply charged particles can easily be distinguished from singly charged particles by the SP2). 


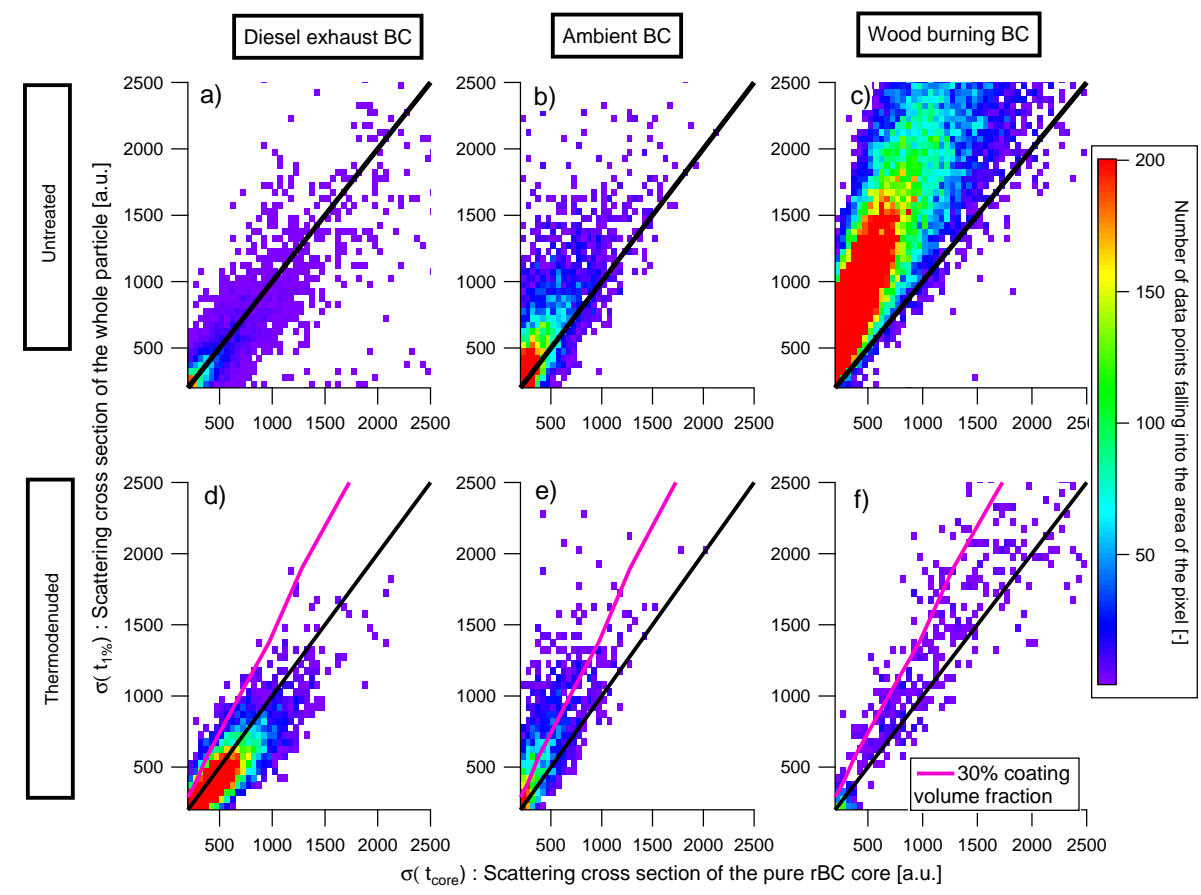

Fig. 4. Estimate of the coating on untreated (top panels) and thermodenuded (bottom panels) samples: diesel exhaust (a, d), ambient (b, e), wood burning $(\mathbf{c}, \mathbf{f})$. The data points corresponding to uncoated particles will lie around the one-to-one line while coated particle data points will be shifted above it. The pink lines (copied from Fig. 2) represent the calculated scattering cross sections for $30 \%$ coating volume fraction and assuming refractive indices of $2.26+1.26 \mathrm{i}$ and 1.5 for BC core and coating, respectively (see Sect. 2.2.2).

The mass-selected $\mathrm{BC}$ particles were then sampled by the SP2 in order to determine the incandescence signal amplitude as a function of the particle mass.

\section{Results and discussion}

\subsection{Residual coating after thermodenuder}

Accurate SP2 calibration curves for ambient $\mathrm{rBC}$ and combustion exhaust can only be recorded with the experimental setup shown in Fig. 3b, if the particles selected by the APM are $100 \% \mathrm{rBC}$. In order to test this caveat, i.e. to test the thermodenuder efficiency, the presence or absence of non$\mathrm{BC}$ coatings on the particles as delivered to the APM and SP2 was checked using the time dependence of the SP2's scattering signals as explained in Sect. 2.2.1.

The scattering cross section of the unaltered particle, $\sigma\left(t_{1} \%\right)$, is compared in Fig. 4 to the scattering cross section of the pure $\mathrm{rBC}$ core $\sigma\left(t_{\text {core }}\right)$. In the absence of a coating, both pure $\mathrm{rBC}$ core and whole particle diameters are identical and consequently the corresponding scattering cross sections should agree and the data points in Fig. 4 should lie around the one-to-one line. In the presence of a coating the unaltered particle will have a larger scattering cross section than the rBC core only and the data points in Fig. 4 will lie above the one-to-one line. The number of data points in Fig. 4 cannot be compared between different panels for several reasons: sampling durations are different, and panels $\mathrm{a}-\mathrm{c}$ are from polydisperse samples, while panels $\mathrm{d}-\mathrm{f}$ are from multiple monodisperse measurements. The scattering cross sections lower than 200 units are not shown in Figs. 4 and 7 as they are unreliable (see Sect. 2.2.2).

The data points of the untreated (not thermodenuded) diesel exhaust particles scatter around the one-to-one line (Fig. 4a), which indicates essentially no coating on the BC particles. This results is consistent with the study by Chirico et al. (2010), who reported organic mass fractions of $\sim 15 \%$ for the same diesel car. The data points of the thermodenuded diesel exhaust (Fig. 4d) also scatter around the one-to-oneline and the diesel exhaust calibration curve is therefore expected to be reliable as it is not biased by the presence of remaining non-BC matter.

The data of untreated wood burning (WB) exhaust indicate a substantial coating upon emission (Fig. 4c). This result also confirms previous findings where WB exhaust from this burner have been shown to have a high OC to EC ratio (Heringa et al., 2011). Furthermore, alkali salts such as potassium sulfate or potassium chloride are known to be common constituents of WB (Dusek et al., 2005) and will not be removed in the thermodenuder due to their high boiling point $\left(1689^{\circ} \mathrm{C}\right.$ and $1420^{\circ} \mathrm{C}$, respectively). In the SP2, however, the particles reach temperatures of typically $\sim 4000 \mathrm{~K}$ (Schwarz et al., 2006) and these compounds will evaporate before the maximum of the incandescence signal is reached. 


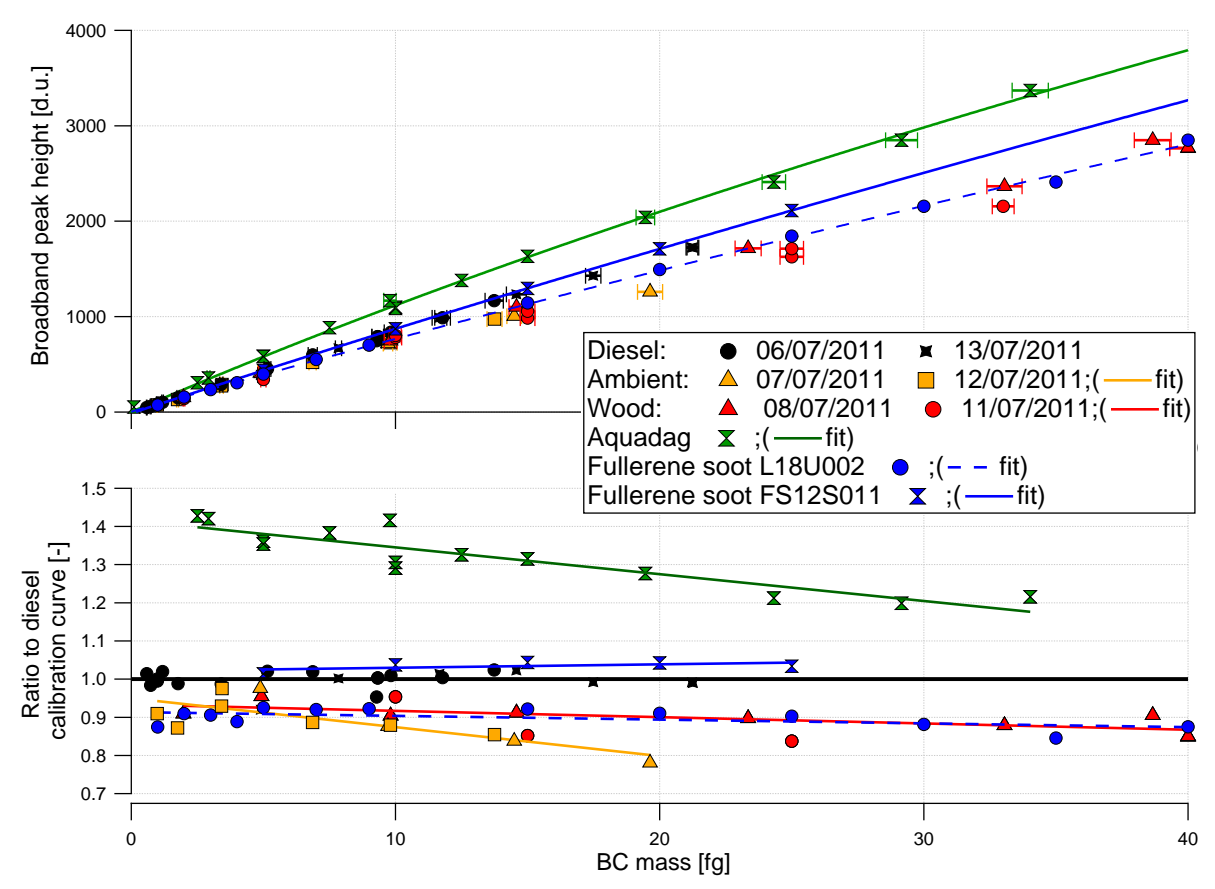

Fig. 5. Sensitivity of the SP2 to different BC types. (a) Calibration curves and (b) ratio to the diesel exhaust calibration. By definition, the diesel calibration is unity. Note: the calibration curve of BC from ambient aerosol is most likely biased towards too high mass values, as the selected particles were not $100 \%$ pure rBC. The errors bars represent one standard deviation of the mass measurement.

The presence of such substantial coatings increases the risk of incomplete coating removal by thermal treatment. Indeed, the thermodenuded WB exhaust data indicate a small remaining coating (Fig. 4f) though too few data points are available for a clear statement. The wood burning calibration curves are therefore likely to have a small bias due to an overestimation of $\mathrm{rBC}$ mass.

In the same way, the untreated ambient BC containing particles data show a substantial fraction of particles initially coated (Fig. 4b). Kondo et al. (2011) showed that pure organic particles composed of saccharides, dicarboxylic acids or aromatic acids lost $\geq 95 \%$ of their volume when heated up to $400^{\circ} \mathrm{C}$, however, the removal efficiency was as low as $20-$ $60 \%$ for humic-like substances. It can indeed be seen that the thermodenuded ambient $\mathrm{BC}$ data points are centered above the one-to-one line in Fig. 4e, indicating that the coating is not totally removed. The volume fraction of the remaining non-BC matter is most likely below $30 \%$ on average, as indicated by the pink line in Fig. 4e, which is taken from the sensitivity analysis presented in Sect. 2.2.2 and Fig. 2. The corresponding mass fraction will be slightly lower, depending on the density of the coating.

The ambient calibration can therefore also be expected to have a small bias due to the overestimation of rBC mass. These conclusions have to be kept in mind during the interpretation of the calibration curves presented in Sect. 3.2.

\subsection{SP2 sensitivity to BC type}

We report herein the SP2 calibration curves for different BC types, namely the observed SP2 incandescence signal amplitude in dependence of the mass selected by the APM, in order to identify the most suitable calibration material for SP2 measurements in ambient air and to quantify the uncertainty of measured $\mathrm{rBC}$ mass concentration due to SP2 calibration uncertainty.

The SP2's response to thermodenuded diesel exhaust rBC (Fig. 5a, black markers) is a linear function of rBC mass. As previously described in Sect. 3.1, this calibration curve is unbiased by residual coatings and therefore reliable. This diesel exhaust calibration is expected to be representative of the SP2's sensitivity to ambient rBC where fossil fuel combustion is the dominant BC source. This applies to most urban locations (e.g. Szidat et al., 2006), whereas different sources such as biomass burning, burning of biofuel or urban waste may be dominant at other locations (Bond et al., 2004).

The calibration curve using thermodenuded WB exhaust is below the diesel exhaust calibration curve (Fig. 5a, red markers). The difference between wood combustion $\mathrm{rBC}$ and diesel exhaust $\mathrm{rBC}$ is $\sim 14 \%$ up to a $\mathrm{rBC}$ mass of $40 \mathrm{fg}$ (Fig. 5b, red markers). A small remaining coating on the particle has been identified in Sect. 3.1 which results in a small bias in the calibration curve. The SP2 sensitivity should therefore differ by less than the measured $14 \%$ between diesel and WB rBC. 
The calibration obtained from thermodenuded ambient $\mathrm{rBC}$ agrees with the diesel exhaust calibration within $\leq 10 \%$ in the range below $5 \mathrm{fg} \mathrm{rBC}$ (Fig. $5 \mathrm{~b}$ ). It is however $\sim 10$ $20 \%$ lower than the diesel exhaust calibration in the range 5-20 fg rBC. Ambient data seem to agree with the WB calibration, however, likely for the wrong reason. Indeed, the ambient calibration is likely biased to higher masses in Fig. 5 as indicated by the analysis of the time dependent scattering cross section discussed in Sect. 3.1. The bias in mass was estimated to be most likely below $30 \%$. Consequently an unbiased ambient calibration would still fall close to the diesel calibration. This confirms that the diesel exhaust calibration curve can be considered to represent the SP2's sensitivity to ambient $\mathrm{rBC}$ where fossil fuel emissions are the dominant source of BC.

As a conclusion, the diesel exhaust calibration curve represents ambient $\mathrm{rBC}$ when dominated by diesel exhaust $\mathrm{rBC}$ and likely also $\mathrm{WB}$ rBC with little uncertainty. In addition, APM-based SP2 calibrations using fresh thermodenuded diesel exhaust is considered to provide the ideal SP2 calibration approach for ambient SP2 measurement in any area with dominant contribution from fossil fuel combustion to total BC mass. Application of a diesel exhaust based SP2 calibration for measurement of $\mathrm{rBC}$ from wood burning may possibly result in an undererestimation of the actual $\mathrm{rBC}$ mass, however, the bias will likely be less than $14 \%$.

However, only few research groups can perform such diesel exhaust calibrations. Therefore it is important to find a commercially available calibration material that matches the SP2's sensitivity to diesel exhaust.

The calibration curve of untreated Aquadag ${ }^{\circledR}$ (Fig. 5a, green markers) is clearly above those of all other BC types with a difference linearly decreasing from $\sim 40 \%$ at $2 \mathrm{fg}$ to $\sim 20 \%$ at $24 \mathrm{fg}$ (Fig. 5b). This result is consistent with Moteki and Kondo (2010) who reported $\sim 40 \%$ higher sensitivity of the SP2 to Aquadag ${ }^{\circledR}$ compared to fullerene soot in the range $\leq 10 \mathrm{fg} \mathrm{rBC}$. Aquadag ${ }^{\circledR}$ has two main advantages such as a stable effective density across different batches (Gysel et al., 2011) and reproducible SP2 calibration curves across different batches, however, the rBC mass in ambient aerosols will be underestimated when using Aquadag ${ }^{\circledR}$ calibrations.

The calibration curve of the untreated fullerene soot from batch FS12S011 (Fig. 5a, blue solid line) agrees within 5\% with the diesel exhaust BC calibration curve (Fig. 5b, black lines). However, the other batch (L18U002) is clearly lower than the diesel exhaust calibration with a difference increasing from $\sim 10 \%$ at $2 \mathrm{fg}$ up to $\sim 13 \%$ at $40 \mathrm{fg}$ (Fig. 5a and b, dashed blue line). Possible reasons for this difference will be discussed in Sect. 3.3. The batch L18U002 agrees better with ambient and WB rBC, however, the ambient and WB$\mathrm{rBC}$ calibrations are likely biased to the higher masses. The agreement of the fullerene soot calibrations with diesel exhaust $\mathrm{rBC}$ is within $\sim 13 \%$ or less depending on the batch.

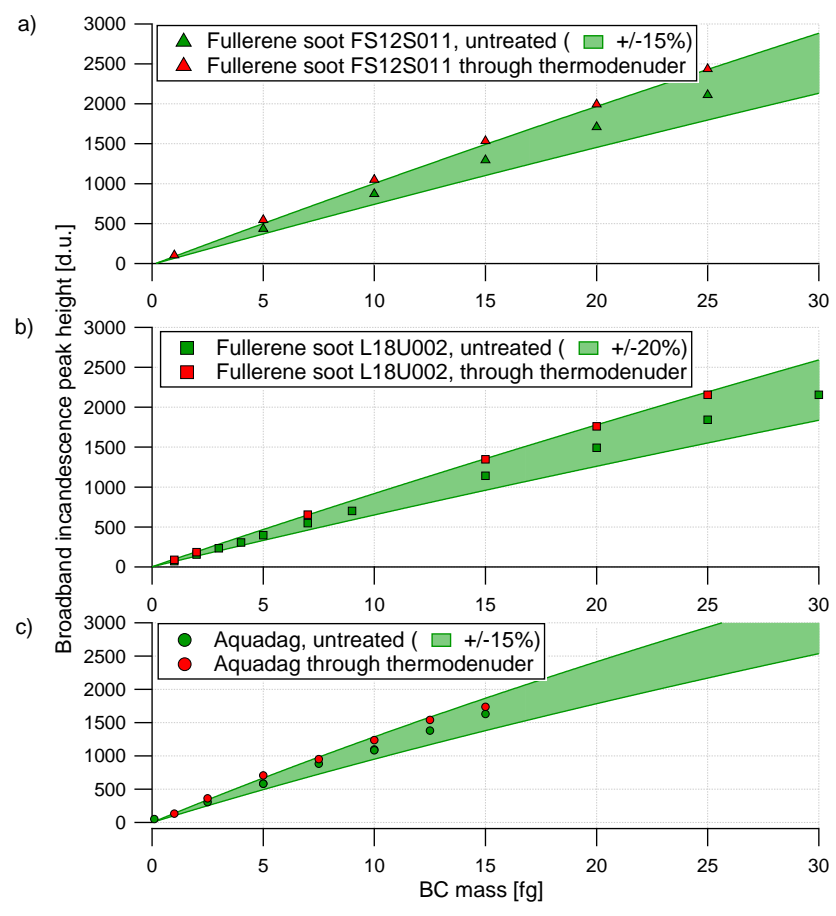

Fig. 6. Thermodenuder effect on SP2 calibration using commercially available products: measurement of the SP2 sensitivity with and without thermodenuder of (a) fullerene soot batch FS12S011, (b) fullerene soot batch L18U002, (c) Aquadag ${ }^{\circledR}$.

This good agreement between fullerene soot and diesel exhaust rBC confirms results reported by Moteki and Kondo (2010) where the slopes of the calibration curves of ambient $\mathrm{rBC}$ in an urban environment and fullerene soot agree within $\sim 10 \%$ in the mass range below $10 \mathrm{fg}$.

As a conclusion, Aquadag ${ }^{\circledR}$ calibrations based SP2 measurements of ambient air will result in a systematic underestimation of measured $\mathrm{rBC}$ mass concentrations and massderived $\mathrm{BC}$ core diameter values. Fullerene soot is not perfectly reproducible from batch-to-batch. Nevertheless, it is the recommended calibration material for ambient SP2 measurements, which should make an absolute accuracy within $\sim 5-13 \%$ possible. The effective density of a certain sample of fullerene soot has been shown to be stable over time and insensitive to aerosol generation procedures (Gysel et al., 2011), such that DMA-based SP2 calibrations are possible. For standard ambient applications it is recommended that all SP2s are calibrated (by the manufacturer or the research groups themselves) with fullerene soot from the same batch (of which a large amount is characterized for effective density and centrally stored for distribution to all users).

\subsection{Thermodenuder effect on calibration materials}

The calibration curves of Aquadag ${ }^{\circledR}$ and fullerene soot shown in Fig. 5 are for untreated particles, as this is the common calibration practice among SP2 users. However, 


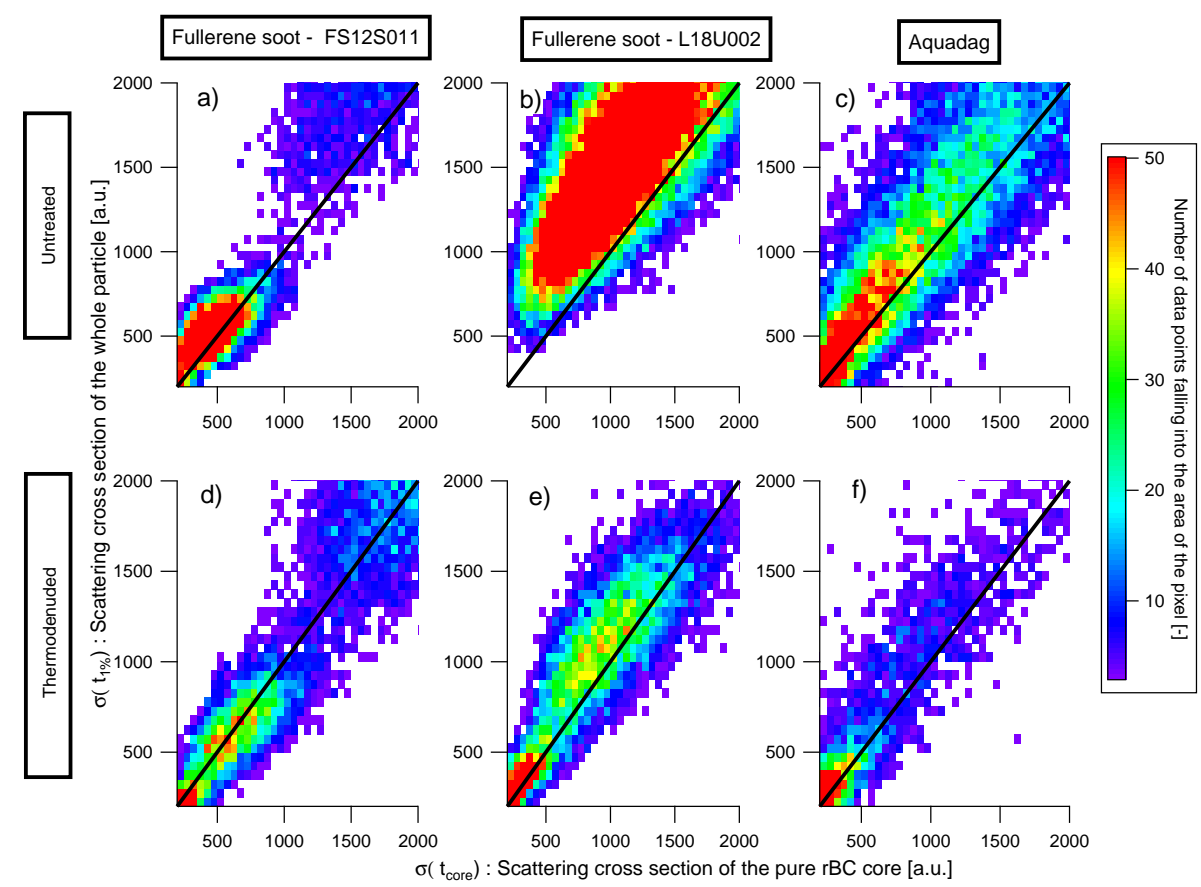

Fig. 7. Estimate of the coating on untreated (top panels) and thermodenuded (bottom panels) samples: fullerene soot batch FS12S011 (a, d), fullerene soot batch L18U002 (b, e), Aquadag ${ }^{\circledR}(\mathbf{c}, \mathbf{f})$. The data points corresponding to uncoated particles will lie around the one-to-one line while coated particle data points will be shifted above it.

Gysel et al. (2011) already pointed out that thermodenuded Aquadag ${ }^{\circledR}$ and fullerene soot particles produce a higher incandescence signal than untreated particles of equal total particle mass. They speculated that this effect is most likely caused by a small amount of non-refractory coatings on the untreated calibration particles. In order to further quantify this effect, additional SP2 calibration curves have also been measured for thermodenuded Aquadag ${ }^{\circledR}$ and fullerene soot. The experimental setup with optional thermodenuder shown in Fig. 3a was chosen for this purpose.

The results presented in Fig. 6 show that the calibration curves of the thermodenuded particles are clearly above those of the untreated particles, both for Aquadag ${ }^{\circledR}$ and fullerene soot. Mennella et al. (1995) showed that carbon black's chemical structure and absorption properties are altered by heating the sample to $400{ }^{\circ} \mathrm{C}$ for several hours. The thermodenuder effect on the SP2's sensitivity to Aquadag ${ }^{\circledR}$ and fullerene soot is unlikely due to this phenomenon as the particles are only heated for a few seconds. On the other hand, a small remaining coating on the particles can shift the calibration. The presence or absence of coatings on the Aquadag ${ }^{\circledR}$ and fullerene soot particles, untreated or thermodenuded has been investigated by analysis of the timedependent scattering cross section (Sect. 3.1) in the same way as for the diesel exhaust, wood combustion and ambient samples. Figure 7 shows the comparison of the scattering cross section of the unaltered particle with that one of the pure $\mathrm{BC}$ core. In the case of the fullerene soot batch FS12S011, the calibration curve increases by $\sim 15 \%$ in the range $2-25 \mathrm{fg}$ (Fig. 6a). A small amount of coating could be measured on the untreated particles (Fig. 7a) while this coating is significantly reduced after treatment (Fig. 7d). It is therefore clear that the shift in the calibration is due to an increase of the rBC mass fraction in the particles by thermodenuding. For the other batch of fullerene (L18U002), the calibration curve increases by $\sim 20 \%$ in the range $2-25 \mathrm{fg}$ (Fig. 6b). A substantial coating could also be measured on the untreated sample (Fig. 7b) which is not totally removed by thermodenuding (Fig. 7e). Removal of a larger amount of coating from this batch is consistent with the larger effect of the thermodenuder compared to the other batch (Fig. 7a and $b$ ). The difference in the amount of coating may also account for the difference between the calibration curves of the two untreated samples (Fig. 5).

In the case of the Aquadag ${ }^{\circledR}$, the calibration curve increases by $\sim 15 \%$ in the range $2-15$ fg (Fig. 6c). A little amount of coating can be seen on the untreated Aquadag ${ }^{\circledR}$ (Fig. 7c) as well as on the thermodenuded sample (Fig. 7f). The thermodenuder does not affect the coating on the Aquadag ${ }^{\circledR}$ sample significantly.

The effect of the thermodenuder on the calibration standard raises the question whether a thermodenuder should be used for SP2 calibrations. From the above results, we do not 
recommend the use of a thermodenuder for the following reasons:

- Untreated fullerene soot represents ambient $\mathrm{rBC}$ in terms of SP2 response.

- The use of untreated fullerene soot and Aquadag ${ }^{\circledR}$ has been common pratice so far.

- Aquadag ${ }^{\circledR}$ would disagree even more with ambient rBC with thermal treatment.

\section{Conclusion}

Thermodenuded diesel exhaust has been found to be the ideal calibration material for SP2s as it represents the second main fraction of atmospheric $\mathrm{BC}$ in most locations and because its low $\mathrm{OC}$ to $\mathrm{BC}$ ratio upon emission reduces the risk of bias from incomplete coating removal. In addition the SP2 response to thermodenuded diesel exhaust is in agreement with that of ambient $\mathrm{rBC}$ within $16 \%$ ( $\leq 15 \mathrm{fg}$ ). At least part of this difference is due to incomplete removal of non-rBC coatings before mass selection of the ambient $\mathrm{rBC}$.

The SP2 is a little less sensitive to $\mathrm{rBC}$ from wood burning particles than to $\mathrm{rBC}$ from diesel exhaust particles $(\sim 14 \%$ up to $40 \mathrm{fg}$ ). At least part of this difference is also likely due to incomplete removal of non-rBC coatings before mass selection of the wood burning rBC. However, access to an aerosol particle mass analyzer is required to perform such SP2 calibrations.

The SP2's sensitivity to untreated fullerene soot has been shown to agree within $\pm 10 \%$ with $\mathrm{rBC}$ from diesel exhaust in the range $\leq 40 \mathrm{fg}$ while two different batches of fullerene soot differed by up to $15 \%$ between themselves. This difference between batches is likely the result of different amounts of non-refractory material on the fullerene soot. The SP2 is $30-40 \%$ more sensitive to Aquadag ${ }^{\circledR}$ in the range $\leq 15 \mathrm{fg}$ than to rBC from diesel exhaust.

If a diesel exhaust based calibration is not possible, fullerene soot similar to FS12S011 with as little as possible non-refractory matter should be solicited as a future reference for calibration of all SP2s. Aquadag ${ }^{\circledR}$ cannot be recommended for ambient applications.

These findings highlight the importance of the calibration material choice in achieving accurate rBC measurement using the SP2. However, this accuracy also depends on the choice of the material's effective density when using a DMA in order to calibrate the SP2. Previous studies based on Aquadag ${ }^{\circledR}$ have used a size-independent value of $1000 \mathrm{~kg} \mathrm{~m}^{-3}$ which is $\sim 55 \%$ higher than the true value of $\sim 650 \mathrm{~kg} \mathrm{~m}^{-3}$ (Gysel et al., 2011) in the mass range 5-10 fg, where the atmospheric rBC mass size distribution typically peaks (Schwarz et al., 2008a). At the same time, the SP2 has been shown to be $\sim 35 \%$ more sensitive to Aquadag ${ }^{\circledR}$ than to
$\mathrm{rBC}$ from diesel exhaust in the same mass range. The combination of both counteractive effects will result in reasonable $\mathrm{rBC}$ results.

\section{Supplementary material related to this article is available online at: http://www.atmos-meas-tech.net/5/ 1031/2012/amt-5-1031-2012-supplement.pdf.}

Acknowledgements. The authors would like to thank J. P. Schwarz for providing a batch of fullerene soot. Financial support was received from the Swiss National Science Foundation and from the Competence Center Environment and Sustainability (CCES) of the ETH Domain (IMBALANCE project).

Edited by: J. Curtius

\section{References}

Arnott, W. P., Rogers, C. F., Jin, T. F., and Bruch, R.: Photoacoustic spectrometer for measuring light absorption by aerosol: instrument description, Atmos. Environ., 33, 2845-2852, 1999.

Bond, T. C. and Bergstrom, R. W.: Light absorption by carbonaceous particles: An investigative review, Aerosol Sci. Tech., 40, 27-67, 2006.

Bond, T. C., Streets, D. G., Yarber, K. F., Nelson, S. M., Woo, J. H., and Klimont, Z.: A technology-based global inventory of black and organic carbon emissions from combustion, J. Geophys. Res., 109, D14203, doi:10.1029/2003JD003697, 2004.

Burtscher, H., Baltensperger, U., Bukowiecki, N., Cohn, P., Hüglin, C., Mohr, M., Matter, U., Nyeki, S., Schmatloch, V., Streit, N., and Weingartner, E.: Separation of volatile and non-volatile aerosol fractions by thermodesorption: instrumental development and applications, J. Aerosol Sci., 32, 427-442, 2001.

Chirico, R., DeCarlo, P. F., Heringa, M. F., Tritscher, T., Richter, R., Prévôt, A. S. H., Dommen, J., Weingartner, E., Wehrle, G., Gysel, M., Laborde, M., and Baltensperger, U.: Impact of aftertreatment devices on primary emissions and secondary organic aerosol formation potential from in-use diesel vehicles: results from smog chamber experiments, Atmos. Chem. Phys., 10, 11545-11563, doi:10.5194/acp-10-11545-2010, 2010.

Dusek, U., Frank, G. P., Helas, G., Iinuma, Y., Zeromskiene, K., Gwaze, P., Hennig, T., Massling, A., Schmid, O., Herrmann, H., Wiedensohler, A., and Andreae, M. O.: "Missing" cloud condensation nuclei in peat smoke, Geophys. Res. Lett., 32, L11802, doi:10.1029/2005GL022473, 2005.

Ehara, K., Hagwood, C., and Coakley, K. J.: Novel method to classify aerosol particles according to their mass-to-charge ratio Aerosol particle mass analyser, J. Aerosol Sci., 27, 217-234, 1996.

Gao, R. S., Schwarz, J. P., Kelly, K. K., Fahey, D. W., Watts, L. A., Thompson, T. L., Spackman, J. R., Slowik, J. G., Cross, E. S., Han, J. H., Davidovits, P., Onasch, T. B., and Worsnop, D. R.: A novel method for estimating light-scattering properties of soot aerosols using a modified single-particle soot photometer, Aerosol Sci. Tech., 41, 125-135, 2007. 
Gysel, M., Laborde, M., Olfert, J. S., Subramanian, R., and Gröhn, A. J.: Effective density of Aquadag and fullerene soot black carbon reference materials used for SP2 calibration, Atmos. Meas. Tech., 4, 2851-2858, doi:10.5194/amt-4-2851-2011, 2011.

Heringa, M. F., DeCarlo, P. F., Chirico, R., Tritscher, T., Dommen, J., Weingartner, E., Richter, R., Wehrle, G., Prévôt, A. S. H., and Baltensperger, U.: Investigations of primary and secondary particulate matter of different wood combustion appliances with a high-resolution time-of-flight aerosol mass spectrometer, Atmos. Chem. Phys., 11, 5945-5957, doi:10.5194/acp-11-59452011, 2011.

Kondo, Y., Sahu, L., Moteki, N., Khan, F., Takegawa, N., Liu, X., Koike, M., and Miyakawa, T.: Consistency and traceability of black carbon measurements made by laser-induced incandescence, thermal-optical transmittance, and filter-based photoabsorption techniques, Aerosol Sci. Tech., 45, 295-312, 2011.

Liu, D., Flynn, M., Gysel, M., Targino, A., Crawford, I., Bower, K., Choularton, T., Jurányi, Z., Steinbacher, M., Hüglin, C., Curtius, J., Kampus, M., Petzold, A., Weingartner, E., Baltensperger, U., and Coe, H.: Single particle characterization of black carbon aerosols at a tropospheric alpine site in Switzerland, Atmos. Chem. Phys., 10, 7389-7407, doi:10.5194/acp-10-73892010, 2010.

Matsui, H., Kondo, Y., Moteki, N., Takegawa, N., Sahu, L. K., Zhao, Y., Fuelberg, H. E., Sessions, W. R., Diskin, G., Blake, D. R., Wisthaler, A., and Koike, M.: Seasonal variation of the transport of black carbon aerosol from the Asian continent to the Arctic during the ARCTAS aircraft campaign, J. Geophys. Res., 116, D05202, doi:10.1029/2010JD015067, 2011.

Mennella, V., Colangeli, L., Blanco, A., Bussoletti, E., Fonti, S., Palumbo, P., and Mertins, H. C.: A Dehydrogenation Study of Cosmic Carbon Analog Grains, Astrophys. J., 444, 288-292, 1995.

Moteki, N. and Kondo, Y.: Effects of mixing state on black carbon measurements by laser-induced incandescence, Aerosol Sci. Tech., 41, 398-417, 2007.

Moteki, N. and Kondo, Y.: Method to measure time-dependent scattering cross sections of particles evaporating in a laser beam, $\mathrm{J}$. Aerosol Sci., 39, 348-364, 2008.

Moteki, N. and Kondo, Y.: Dependence of Laser-Induced Incandescence on physical properties of black carbon aerosols: measurements and theoretical interpretation, Aerosol Sci. Tech., 44, 663-675, 2010.

Moteki, N., Kondo, Y., and Nakamura, S.: Method to measure refractive indices of small nonspherical particles: Application to black carbon particles, J. Aerosol Sci., 41, 513-521, 2010.

Nakayama, T., Matsumi, Y., Sato, K., Imamura, T., Yamazaki, A., and Uchiyama, A.: Laboratory studies on optical properties of secondary organic aerosols generated during the photooxidation of toluene and the ozonolysis of alpha-pinene, J. Geophys. Res., 115, D24204, doi:10.1029/2010JD014387, 2010.

Olfert, J. S. and Collings, N.: New method for particle mass classification - the Couette centrifugal particle mass analyzer, J. Aerosol Sci., 36, 1338-1352, 2005.
Petzold, A., Kopp, C., and Niessner, R.: The dependence of the specific attenuation cross-section on black carbon mass fraction and particle size, Atmos. Environ., 31, 661-672, 1997.

Ramanathan, V. and Carmichael, G.: Global and regional climate changes due to black carbon, Nat. Geosci., 1, 221-227, 2008.

Schmid, H., Laskus, L., Abraham, H. J., Baltensperger, U., Lavanchy, V., Bizjak, M., Burba, P., Cachier, H., Crow, D., Chow, J., Gnauck, T., Even, A., Ten Brink, H. M., Giesen, K. P., Hitzenberger, R., Hüglin, C., Maenhaut, W., Pio, C., Carvalho, A., Putaud, J. P., Toom-Sauntry, D., and Puxbaum, H.: Results of the carbon conference international aerosol carbon round robin test stage I, Atmos. Environ., 35, 2111-2121, 2001.

Schwarz, J. P., Gao, R. S., Fahey, D. W., Thomson, D. S., Watts, L. A., Wilson, J. C., Reeves, J. M., Darbeheshti, M., Baumgardner, D. G., Kok, G. L., Chung, S. H., Schulz, M., Hendricks, J., Lauer, A., Karcher, B., Slowik, J. G., Rosenlof, K. H., Thompson, T. L., Langford, A. O., Loewenstein, M., and Aikin, K. C.: Single-particle measurements of midlatitude black carbon and light-scattering aerosols from the boundary layer to the lower stratosphere, J. Geophys. Res., 111, D16207, doi:10.1029/2006JD007076, 2006.

Schwarz, J. P., Gao, R. S., Spackman, J. R., Watts, L. A., Thomson, D. S., Fahey, D. W., Ryerson, T. B., Peischl, J., Holloway, J. S., Trainer, M., Frost, G. J., Baynard, T., Lack, D. A., de Gouw, J. A., Warneke, C., and Del Negro, L. A.: Measurement of the mixing state, mass, and optical size of individual black carbon particles in urban and biomass burning emissions, Geophys. Res. Lett., 35, L13810, doi:10.1029/2008GL033968, 2008a.

Schwarz, J. P., Spackman, J. R., Fahey, D. W., Gao, R. S., Lohmann, U., Stier, P., Watts, L. A., Thomson, D. S., Lack, D. A., Pfister, L., Mahoney, M. J., Baumgardner, D., Wilson, J. C., and Reeves, J. M.: Coatings and their enhancement of black carbon light absorption in the tropical atmosphere, J. Geophys. Res., 113, D03203, doi:10.1029/2007JD009042, 2008 b.

Slowik, J. G., Cross, E. S., Han, J. H., Davidovits, P., Onasch, T. B., Jayne, J. T., Williams, L. R., Canagaratna, M. R., Worsnop, D. R., Chakrabarty, R. K., Moosmüller, H., Arnott, W. P., Schwarz, J. P., Gao, R. S., Fahey, D. W., Kok, G. L., and Petzold, A.: An intercomparison of instruments measuring black carbon content of soot particles, Aerosol Sci. Tech., 41, 295-314, 2007.

Stephens, M., Turner, N., and Sandberg, J.: Particle identification by laser-induced incandescence in a solid-state laser cavity, Appl. Optics, 42, 3726-3736, 2003.

Szidat, S., Jenk, T. M., Synal, H. A., Kalberer, M., Wacker, L., Hajdas, I., Kasper-Giebl, A., and Baltensperger, U.: Contributions of fossil fuel, biomass-burning, and biogenic emissions to carbonaceous aerosols in Zurich as traced by ${ }^{14} \mathrm{C}$, J. Geophys. Res., 111, D07206, doi:10.1029/2005JD006590, 2006.

von Klot, S., Cyrys, J., Hoek, G., Kühnel, B., Pitz, M., Kuhn, U., Kuch, B., Meisinger, C., Hörmann, A., Wichmann, H.-E., and Peters, A.: Estimated personal soot exposure is associated with acute myocardial infarction onset in a case-crossover study, Prog. Cardio. Dis., 53, 361-368, 2011. 